\title{
The challenges of using satellite data sets to assess historical land use change and associated greenhouse gas emissions: a case study of three Indonesian provinces
}

Article

Accepted Version

van Beijma, S., Chatterton, J., Page, S., Rawlings, C., Tiffin, R. and King, H. (2018) The challenges of using satellite data sets to assess historical land use change and associated greenhouse gas emissions: a case study of three Indonesian provinces. Carbon Management, 9 (4). pp. 399-413. ISSN 1758-3004 doi:

https://doi.org/10.1080/17583004.2018.1511383 Available at https://centaur.reading.ac.uk/81279/

It is advisable to refer to the publisher's version if you intend to cite from the work. See Guidance on citing.

To link to this article DOI: http://dx.doi.org/10.1080/17583004.2018.1511383

Publisher: Taylor \& Francis

All outputs in CentAUR are protected by Intellectual Property Rights law, including copyright law. Copyright and IPR is retained by the creators or other copyright holders. Terms and conditions for use of this material are defined in the End User Agreement. 


\section{www.reading.ac.uk/centaur}

\section{CentAUR}

Central Archive at the University of Reading

Reading's research outputs online 
1 The challenges of using satellite datasets to assess historical land use change and associated greenhouse gas emissions - a case study of three Indonesian provinces

Advances in satellite remote sensing and the wealth of earth observation (EO) data now available have improved efforts towards determining and quantifying historical land use and land cover (LULC) change. Satellite imagery can overcome the absence of accurate records of historical land use, however the variability observed in the case study regions demonstrates a number of current challenges.

Differences in spatial coverage, resolution and land cover classification can lead to challenges in analysing historical LULC datasets to estimate LULC change and associated greenhouse gas (GHG) emissions. This paper demonstrates the calculation of LULC change from three existing, open source LULC datasets to show how this can lead to significant variation in estimates of GHG emissions related to differences in land classification methodologies, Earth Observation (EO) input data and period of investigation. We focus on selected regions of Indonesia, where quantifying land use change is important for GHG assessments of agricultural commodities and for evidencing progress against corporate and government deforestation commitments.

Given the significance of GHG emissions arising from LULC change and the increasing need for emissions monitoring, this research highlights a need for consensus building to develop consistency in historic and future LULC change estimates. This paper concludes with a set of recommendations for improvements to ensure consistent LULC mapping.

Keywords: land use/ land cover change, GHG emissions, remote sensing, palm oil, sustainability,

\section{Introduction}

Advances in satellite remote sensing (RS) and the wealth of earth observation (EO) data now available have improved efforts towards accurately mapping Land Use and Land Cover (LULC) and quantifying change [1]. This reduces reliance on e.g. ground-level 
monitoring and improves the resolution of assessments that are currently based on country-level statistics. However, challenges remain, and factors such as the type of data (e.g. optical or radar) and spatial and temporal resolution of satellite data may significantly influence the classification of land use and land cover [1,2]. Several organisations have produced and made openly available LULC datasets based upon the interpretation of optical EO satellite data. These are derived from different satellites, based on different sensors, with variations in return time and LULC classification methodology. In this paper, we analyse uncertainty in greenhouse gas (GHG) emission estimates by calculating LULC change with three historic LULC datasets, with a focus on selected regions of Indonesia where the development of the Palm Oil (PO) industry 40 has been a significant driver of LULC change in recent decades [2].

\section{$41 \quad$ LULC mapping}

Mapping of LULC is one of the key applications of RS technologies and has been carried out for at least 40 years [3]. However, there is little agreement on best practice for LULC mapping. A recent overview of different LULC mapping methodologies is provided by Joshi et al., (2016) [1]. The process of remote sensing image classification is complex and involves many steps, including the determination of a land cover classification system, collection of data sources and selection of a classification algorithm [4]. One of the most important considerations in LULC mapping is the definition of LULC classes. This can be done with a focus on Land Use (purpose for which humans use land) or Land Cover (physical properties of a land surface) [1]. LULC class definitions can be either broad (e.g. Forest, Agriculture, Grassland etc.) or specific (e.g. subdividing agricultural land into Oil Palm, Corn, Banana, etc.). Optimal class definition depends on the specific needs of the user, but, in general, broad classes are better suited for large-scale (continental) LULC mapping. Whilst higher specificity 
55 in land classes is preferable for regional or national-scale land mapping studies [1], it

56 has been shown that using a large number of highly specific classes can lead to

57 misclassification, as differences between classes become small $[5,6]$.

58 Another major consideration when developing a LULC classification scheme is the selection of optimal RS input data. Low resolution (LR) optical sensors (e.g. MODIS,

60 MERIS) have been useful for vegetation mapping at global or continental scale, while

61 medium resolution (MR) satellites (e.g. Landsat TM) are most frequently used for

62 regional LULC mapping [4]. High resolution (HR) satellite data (e.g. DigitalGlobe,

63 SPOT) require greater resource in terms of processing capacity and can be costly when

64 large area coverage needs to be acquired. Therefore, HR data is more likely to be used

65 for validation of smaller areas [4]. Quality of RS imagery can be hampered by persistent

66 cloud cover in tropical regions [2]. Integrated use of Synthetic Aperture Radar (SAR)

67 satellite data, which has high resolution capability and is unaffected by cloud cover, has

68 shown to be improving LULC mapping significantly [1] and is becoming more

69 commonly used in tropical LULC mapping [7].

70 The classification methodology used for LULC mapping is a third major consideration.

71 There is a plethora of image classification algorithms and methodologies available [1].

72 Common methodologies or algorithms range from statistical methods (e.g. Maximum

73 Likelihood Classification (MLC), Principle Component Analysis (PCA)) [8,9], machine

74 learning algorithms (Support Vector Machine (SVM), Random Forest (RF)) [10-12],

75 knowledge-based/decision trees methods $[6,13]$ to visual/manual interpretation of

76 satellite data [12]. Changes in LULC class definitions, RS data input and classification

77 methods over time can lead to issues of consistency and variability in estimates of

78 historical LULC change [2]. 
80 Carbon dioxide emissions from fossil fuel use are relatively well quantified, but GHG

81 emissions from LULC change remain highly uncertain and yet are one of the largest anthropogenic sources of GHG emissions [14]. Land-use changes can cause emissions due to carbon losses in both biomass and soils [15]. Rapid expansion of agriculture for

84 large scale commodity crops can lead to large changes in carbon stocks [16].

85 Understanding emissions from LULC change is key to quantifying life cycle emissions 86 of large scale agricultural commodities, such as PO. Growth in PO production in South87 East Asia, led primarily by Indonesia and Malaysia, has been a key component of meeting growing global demand for bio-based oil in recent decades. Indonesia and Malaysia currently meet more than $85 \%$ of global PO demand, $51 \%$ and $34 \%$ respectively [17]. In

90 these countries, plantations cover an estimated area of $140,000 \mathrm{~km}^{2}$ on both mineral and 91 organic (peat) soils, which has led to large-scale LULC change in the region [2].

92 A historical record of 20-25 years is necessary for LUC emissions to be included in Life Cycle Assessments (LCA). Openly-available satellite data with global coverage, and of 94 sufficient quality, does not widely exist prior to 2000 and, therefore, this period is rarely 95 covered by LULC datasets.

\section{Significance of peat soils}

97 Soils in wetland ecosystems (e.g. peat swamp forests) contain large amounts of organic

98 material, and therefore have high below-ground carbon stocks with carbon densities that 99 may exceed those of the aboveground vegetation [18]. When organic soils are disturbed, 100 and particularly when drained, removing water from the soil pores; oxygen can enter the 101 soil surface and oxidize the soil organic material through biological and chemical 102 processes. Oxidation of soil organic matter leads to a carbon flux to the atmosphere, 
mostly as $\mathrm{CO}_{2}[19]$.

104 GHG emissions after drainage are not constant; they will vary as water tables and peat

105 characteristics change [20]. In typical PO plantation developments on peat soils in

106 Southeast Asia, the initial peatland drainage usually involves a rapid lowering of the

107 water table to depths of around or below $1 \mathrm{~m}$ to over $3 \mathrm{~m}$. In the first few months or

108 years after drainage, the peat surface will change rapidly through a combination of peat

109 oxidation and soil compression. In this transition phase, carbon emissions are higher

110 than during the subsequent, more stable phase i.e. following palm planting, when water

111 levels will generally be maintained at depths of around $0.80 \mathrm{~m}$. From that point

112 onwards, oxidation will proceed at a more or less stable rate until the peat surface is at

113 or close to the local drainage level; dependent upon the peat depth, this may take several

114 decades [20].

115 Any holistic assessment of the carbon emissions arising from LULC change must

116 include both changes in above- and below-ground carbon stocks. The relative

117 proportion of PO plantations on organic soils in Southeast Asia has increased over the

118 last 20 years; these now occupy some $31,000 \mathrm{~km}^{2}$, or approximately $23 \%$ of the total

119 area under PO plantations [21]. It has been shown that this process has been responsible

120 for generating substantial carbon losses and associated GHG emissions from peat

121 decomposition [19].

\section{Aim of this paper}

123 The aim of this paper is to evaluate and compare existing LULC datasets, derived from

124 EO data, to assess historical LULC change and associated GHG emissions. To achieve

125 this, we focus on three Indonesian provinces where large-scale LULC change has been

126 observed in recent decades, much of which is attributable to the development of 
127 plantations.

128 Materials and methods

129 Study area

130 We focus on three areas of interest (AOIs), namely the Indonesian provinces of

131 Northern Sumatra, Riau on the island of Sumatra, and Central Kalimantan on the island

132 of Borneo, Figure 1. These three AOIs, covering approximately one sixth of the total

133 area of Indonesia, lie within an area that is the focus of much attention surrounding land

134 use change emissions [22-24]. All AOIs include areas with peat soils, according to the

135 peat soil map distributed by the Centre for Remote Imaging, Sensing and Processing

136 (CRISP) in Singapore [19]. Additionally, in all three AOIs PO production occurs on

137 both mineral and peat soils, according to PO concession data obtained from Global

138 Forest Watch [25], (Table 1).

\section{LULC data sources}

140 Three open-source, satellite-derived LULC datasets were identified as thematically and

141 spatially relevant for the AOIs, as detailed in Table 2.

142 The Climate Change Initiative (CCI) LULC dataset was developed by the European

143 Space Agency (ESA) CCI Land Cover Initiative, currently available with updates for

144 the period 1992-2015. CCI is a global LULC dataset, with a class definition based on

145 the Land Cover Classification System (LCCS) developed by the United Nations (UN)

146 Food and Agriculture Organization (FAO) [26]. Class definitions are broad, with no

147 specific LULC classes for tree plantations. Quality assessment of the CCI dataset

148 (included in [26]) was based on referencing using higher resolution satellite data or

149 derived products (Landsat, Google Earth, SPOT-Vegetation (SPOT-VGT)) for specific 
150 reference areas, which were chosen to cover all global climatic zones, with subsamples

151 chosen randomly from these areas. The overall accuracy between the CCI 2010 dataset 152 and a reference dataset for 2009 was $74.4 \%$.

153 The CRISP LULC dataset was developed by the Centre for Remote Imaging, Sensing 154 and Processing in Singapore and covers Southeast Asia, with updates for 2000, 2010 155 and 2015. The mapping methodology is well documented [21,27]. The 2015 LULC data 156 update has been developed using a methodology which differs significantly from that 157 used for the 2000 and 2010 updates; CRISP have therefore advised users to avoid 158 comparisons of the 2015 data with older updates for LULC change analysis [21]. The

159 class definition is specific, with two classes for plantations ("Large scale palm

160 plantations" and "Plantation/regrowth"). Quality assessment of the CRISP dataset was

161 carried out by comparing the LULC maps with a total of 1000 random sample plots

162 from very-high resolution satellite data [21]. The total accuracy for the 2015 CRISP 163 dataset was $81.6 \%$.

164 The MoF LULC dataset was developed at the Indonesian Ministry of Forestry, and 165 currently provides irregular updates between 1990 and 2015. In total ten updates are 166 available, of which eight are between 2000 and 2015. There is no accompanying 167 documentation detailing the image classification methodology used for the LULC 168 mapping. However, according to [23], it is primarily based on visual interpretation of 169 Landsat 30x30 m satellite data. There is no indication of whether any quality assurance 170 checks have been carried out. When considering forest cover in Indonesia, comparison 171 between MoF and Global Forest Watch forest cover data [28] indicated agreement in $17290.2 \%$ of the area considered [29]. The MoF LULC classes are specific, identifying two 173 plantation types (general plantation and timber plantation), as well as undisturbed and 174 disturbed forests. 
176 Figure 2 presents an overview of the processing and analysis workflow. After collection

177 of the LULC, AOI boundary and peat soil extent data, the data is pre-processed using

178 the following steps:

- Conversion of LULC data to raster. The MoF data is delivered in vector format, in order to make the dataset comparable in terms of resolution, it was converted to raster with a $100 \times 100 \mathrm{~m}$ spatial resolution.

- Subsetting of LULC and peat soil data per AOI.

- Split of LULC data between peat soil and non-peat soil areas.

- Reprojection of data to the same Universal Transvers Mercator (UTM) zone projection, UTM 47N for North Sumatra and Riau AOI data, UTM 49N for Central Kalimantan.

- Class aggregation of specific LULC classes into broad classes for the crosscomparison of LULC data, detailed below.

\section{Cross-comparison LULC data}

Pairwise comparison of the three LULC datasets was carried out using the Mapcurves analysis [30]. Mapcurves analysis provides a method to compare two categorised maps by cross-referencing, to quantify the similarity between the classifications. This analysis provides insight by calculating the proportion of overlap between each LULC class from one dataset (Map A) and the best overlapping LULC class from another dataset (Map B). The best overlaps for all classes from Map A with classes from Map B are calculated, and the overlap fractions are summed to derive the total agreement between Map A and Map B. This total is named the Goodness of Fit (GoF); a GoF of 1.0 means a perfect fit, a GoF of 0.0 no fit at all. This analysis can be run both ways, i.e. using map 
199 A as the original and using Map B as the reference, or vice versa. The GoF is expressed

200 as a percentage and can therefore be compared across categories and maps.

201 It should be noted that the GoF does not give information about the total area of

202 agreement, as each LULC class has equal influence on the GoF, regardless of its area of

203 presence in the original map. Nor does this analysis provide insight into relative quality

204 of datasets, but gives an indication of the proportion of overlap.

205 To make the three LULC datasets as comparable as possible, LULC classes were

206 aggregated into nine broad classes, based on a general class aggregation utilised for the

207 CCI data [26]: Agriculture, Forest, Grassland, Shrubland, Sparse Vegetation, Wetland,

208 Settlement, Bare and Water.

209 The cross-comparison analysis was run for dates pertaining to two specific years in

210 which all three LULC datasets have an update, 2000 and 2015 (Figure 3a-f).

\section{LULC change analysis}

212 To calculate LULC change for each LULC dataset, changes between each initial update

$213(\mathrm{t} 0)$ to the next update $(\mathrm{t} 1)$ were calculated from the pre-processed data. This was done

214 by comparing each pixel location from the t0 raster data with each corresponding pixel

215 from the $\mathrm{t} 1$ data. If a change in LULC class was observed, the pixel was reclassed as a

216 pixel with a unique value combining the $\mathrm{t} 0$ and $\mathrm{t} 1$ class code. If no change was

217 observed, the pixel was reclassed as no value, see Figure SM1. From this analysis,

218 LULC change maps and tables were produced. Table SM1 provides the time periods

219 used to assess LULC change. For CCI and MoF, these time periods coincide with the

220 updates of the MoF dataset, for CRISP only one period has been used, 2000 to 2010, as

221 the update of CRISP for 2015 cannot be compared for LULC change analysis [21]. The 
222 LULC change is expressed in hectares per year, to correct for varying time intervals

223 between updates.

\section{Carbon emission modelling}

225 To convert LULC change into carbon emission estimates, values for Aboveground 226 Biomass (AGB) and Organic Soil Degradation (OSD) emissions factors were obtained 227 for all the LULC classes of the three datasets. This was done by conducting a review of 228 published literature related to LULC change in Southeast Asia (primarily based on $229[15,20,31-33])$. From this review, average values for AGB and OSD for each LULC 230 class were calculated (Table SM2 and Table SM3). AGB emission factors are expressed 231 in $\mathrm{Mg} \mathrm{C} \mathrm{ha}{ }^{-1}$, the OSD emissions are given in $\mathrm{Mg} \mathrm{C} \mathrm{ha}^{-1} \mathrm{yr}^{-1}$, as these continue for an 232 indefinite period after a LULC change from natural to man-made state [19]. The LULC 233 change data from the selected areas and the AGB and OSD emission values were

234 combined to estimate GHG emissions. The model, Equation 1, is a simplified version 235 of the model in [34], not taking into account the GHG emissions related to peat fire due 236 to additional uncertainty.

$$
E=E_{a}-S_{a}+E_{b o}
$$

where $E$ is the emission estimate, $E_{a}$ is emission from AGB due to LUC, $S_{a}$ sequestration of $\mathrm{CO}_{2}$ from the atmosphere into crop biomass between succeeding land uses and $E_{b o}$ is emission from OSD. A graphical example of the model is provided in

240 Figure SM2. For example, if 1 ha changes from Primary Forest (average AGB $233 \mathrm{Mg}$

$241 \mathrm{C} \mathrm{ha}^{-1}$ ) to Shrubland (average AGB $31 \mathrm{Mg} \mathrm{C} \mathrm{ha}^{-1}$ ) then, for AGB, a total of 233-31=

$242202 \mathrm{Mg} \mathrm{C}$ will be emitted. If subsequently this 1 ha of Shrubland becomes Plantation 243 (average AGB $37 \mathrm{Mg} \mathrm{C}^{-1}$ ) then the net carbon emissions will be 31-37 = -6 $\mathrm{Mg} \mathrm{C}$, 
244 which indicates carbon sequestration.

245 The latest insights with respect to emissions from drained peatlands are reported by

246 IPCC $[20,35]$. The OSD emission factor values used in this paper relate to ongoing

247 oxidation of peat. We exclude additional emissions occurring during the first 5 years

248 after drainage for plantation establishment [20,36], relating to fires [37], and the

249 potential emissions from organic carbon flushed into aquatic ecosystems (e.g. as

250 dissolved organic carbon (DOC), and associated emissions of $\mathrm{CO}_{2}$ and $\mathrm{CH}_{4}$ [38]).

251 These emissions are highly uncertain and would, therefore, obscure the uncertainty in

252 GHG estimates from different LULC datasets. Thus, in our calculations, if Peatswamp

253 Forest on organic soil changes to PO Plantation, the OSD emission related to land

254 conversion is $11 \mathrm{Mg} \mathrm{C} \mathrm{ha}^{-1} \mathrm{yr}^{-1}$.

255 On the basis of [31], who reported that, for mineral soils, the net temporal trend in the

256 soil carbon stock (in the top $30 \mathrm{~cm}$ of soil) was not significantly different from zero in

257 both forest- and non-forest-derived plantations, we assume soil carbon stock neutrality

258 on mineral soils used for oil palm cultivation.

259 Results and discussion

260 Cross-comparison LULC data (Mapcurves)

261 The Mapcurve plots with the highest consistencies for each area and date are visualised

262 in Figure 3. The highest GoF values are observed for either a combination of CCI as

263 Original and CRISP as Reference map or the combination of MoF as Original and

264 CRISP as Reference map. The highest GoF observed is 0.575 for North Sumatra in

2652015 , by combining MoF and CRISP, which means there is 57.5\% class agreement

266 between these maps. All other combinations lead to lower GoF values (see Tables SM4 
and Table SM5). The two data types most dissimilar are the MoF and CCI datasets

268 (generally less than $40 \%$ class agreement).

269 The Mapcurve analysis shows large inconsistencies between LULC datasets, even after 270 aggregation of specific LULC classes, to make the datasets more comparable. Other 271 comparative studies of LULC datasets have also observed this [39-41], either by means 272 of the Mapcurves analysis, or by analysing spatial overlap of similar classes on a pixel273 by-pixel basis. Of these studies, the maximum observed Mapcurve value was 0.53 [41], while in a pixel-by-pixel based analysis the highest agreement was found to be $62 \%$ [40]. This shows that, even after aggregation of specific LULC classes into broader

276 classes, high levels of agreement between LULC maps of similar age cannot be 277 assumed.

Differences between LULC maps can be caused by a number of factors [42], including

279 data quality, spatial and temporal resolution, LULC classification approaches,

280 algorithms and aggregation. Data quality can be limited in tropical regions, due to

281 persistent cloud cover and therefore a limited number of useful satellite acquisitions. If

282 sufficient temporal resolution is available, there is better chance that high quality

283 imagery can be obtained in a certain period.

284 Spatial resolution dictates the smallest mapping unit. In general, if a pixel is sufficiently 285 small, more specific LULC can be distinguished. Lower spatial resolution pixels often 286 cover more than one specific LULC class, and therefore the LULC class definition must 287 be more generic, as for CCI. Spectral resolution influences how well LULC classes can 288 be technically distinguished. MODIS data, which underlies the CRISP dataset, operates 289 in 34 spectral bands [43], whereas Landsat- 8 operates in 11 bands [44]. This means that 290 even though MODIS has a spatially lower resolution than Landsat, through its superior 
291 spectral resolution, MODIS might be able to detect more subtle variations in LULC

292 than Landsat.

293 As noted above, a several classification algorithms were used to develop the LULC

294 datasets, which have an effect on differences in mapping results. In general, pixel-based

295 classifiers tend to lead to high heterogeneity in the resulting LULC map, as each pixel is

296 individually classified. Therefore, it is currently more common to include a clustering

297 step in the classification process, as this has been found to positively influence the map

298 accuracy $[45,46]$. The MoF dataset is based on visual interpretation of satellite data,

299 which depends on the interpretation skills of each person working on the LULC maps,

300 which can be subjective [47]. LULC class definition can impact how readily LULC

301 datasets can be compared. Aggregation of specific LULC classes into broad classes can

302 overcome this problem to a large extent, although it is not always clear to which broad

303 class a specific class might belong.

\section{LULC change}

305 For each LULC dataset, LULC change has been calculated for each period between

306 updates (shown in Table SM3). The LULC change observed in each area is presented

307 for North Sumatra (Figure 4), Riau (Figure 5) and Central Kalimantan (Figure 6), The

308 LULC change is averaged to give LULC change in hectares per year, to make the

309 differing periods between updates directly comparable.

310 According to the MoF dataset, for each AOI, one 'peak change period' with an extreme

311 LULC change is recorded. In North Sumatra this is 2006-2009, 2012-2013 in Riau, and

312 2013-2015 in Central Kalimantan. From the data (Table SM6), the North Sumatra peak

313 change period is 4.7 times larger than the average for 2000-2015, 2.5 times larger than

314 average for the Riau peak change period and 3.8 times larger than the average in Central 
315 Kalimantan. It is questionable whether these changes, visible in the RS data, are related

316 to 'actual observed' LULC change in the AOI, which we define as change that can be

317 seen at ground level (corroborated by field observations), or have other causes. Table 3

318 shows the largest contributors to these peak change periods, according to the MoF

319 datasets. Analysis shows that for each occurrence the MoF class 'Dry Rice Land Mixed

320 with Scrub' was involved, either by transition from this class to 'Dry Rice Land' (in

321 North Sumatra) or transition into it from 'Scrubland' (both Riau and Central

322 Kalimantan). The class 'Dry Rice Land Mixed with Scrub' can be interpreted as a

323 transition class between Rice Land and Scrubland, or an ecotone. Defining class

324 boundaries for ecotones is often difficult when making observations in the field; it is

325 even more challenging when interpreting RS data [48]. Due to the magnitude of these

326 peak change periods, it is unlikely that they are related to actual changes in LULC, but

327 more likely related to different interpretation of RS data or methodological shift

328 between MoF updates. However, the influence of this mapping effect on the LULC

329 change observed in Central Kalimantan in 2013-2015 is relatively small, and the

330 majority of LULC change estimated for this period can be attributed to 'actual

331 observed' LULC change at ground level.

332 The CRISP maps consistently give higher estimates for land use change than either the

333 CCI or MoF maps. The annual LULC change estimated by CRISP is between 6.1 and

33412.8 times larger than the LULC change from CCI for the AOIs. For CRISP to MoF, the

335 difference ratios for LULC change lie between 2.2 and 3.8.

336 Temporal correlations between $\mathrm{MoF}$ and CCI data are plotted in Figure 7. As CRISP

337 only provides one update (between 2000 and 2010) this dataset has not been included.

338 The MoF LULC change values have been corrected for the peak change periods

339 described above, to get a better comparison of actual observed LULC change between 
$340 \mathrm{CCI}$ and MoF datasets. The strongest temporal correlation is shown in North Sumatra,

341 with an $\mathrm{R}^{2}$-value of 0.7978 , while those for Riau and Central Kalimantan are much

342 lower.

343 The LULC change analysis shows little agreement between LULC datasets in the AOIs.

344 Whilst some inconsistency can be attributed to methodological factors, not all can be 345 explained directly.

\section{GHG Emissions}

347 Large variability in GHG emissions can be observed for estimates made using the

348 different LULC datasets, Table 4 and Table 5 (see also Figure SM3, Figure SM4 and

349 Figure SM5). GHG emissions estimates from CRISP data (2000-2010 only) are

350 considerably higher than those from both CCI and MoF data, while those from MoF for

351 the period 2011-2015 are generally much higher than the estimates from CCI (Table 5).

352 For Riau and Central Kalimantan, this is partly due to the MoF data inconsistency

353 related to the classification of 'Scrubland' and 'Dry Rice Land Mixed with Scrub'. The

354 peak change periods are also visible, with a peak in emissions in Riau in 2012-2013

355 (Figure SM4) and in Central Kalimantan in 2013-2015 (Figure SM5).

356 These results, which illustrate considerable variability in GHG emission estimates from

357 the different LULC datasets, are supported by other studies, e.g. Agus et al. (2010) [34],

358 estimated that carbon emissions from LULC change studies related to the PO industry

359 in Kalimantan differed by a factor of 4.7.

\section{GHG emission maps}

361 The GHG emission estimates per dataset, area and time period can also be displayed

362 geographically in maps of GHG emissions (Figure 8). The highest modelled GHG 
363 emissions occur in areas with peat soils, primarily in Riau and Central Kalimantan.

364 However, there are also regions where net carbon sequestration occurs, likely related to

365 conversion of low biomass LULC (bare areas, shrub), to higher biomass LULC

366 (plantations). Bare and shrubland areas may be the result of previous deforestation,

367 which highlights the need for sufficient historic data to understand and account for

368 emissions from LULC change over a longer period, especially in peat soil areas. Several

369 methods exist to attribute these emissions to a product, depending on the data available

370 [49]. For LCA, the impact of land use change should include all direct land use change

371 occurring 20 years (or one full harvest, whichever is longer) prior to the assessment.

372 The total GHG emissions (or removals) arising from LULC change over this period

373 would be allocated equally to each year of the period [50].

\section{Carbon emission factors}

375 The values for emissions from AGB and OSD, derived from literature, are key to the

376 GHG emissions calculations in this study. For plantations, the AGB value used in this

377 study is $37 \mathrm{Mg} \mathrm{C} / \mathrm{ha}$, based on a time-averaged value for AGB [15]. However, AGB

378 values of $57.5 \mathrm{Mg} \mathrm{C} / \mathrm{ha}$ have been reported for plantations at full maturity [51]. To

379 understand this sensitivity, results were calculated using this value (Table SM7). In all

380 but one instance, annual emissions are reduced by $1 \%-33 \%$ when using the higher

381 carbon stock value for plantation classes. In one case emissions increase (MoF, 2011-

3822015 for North Sumatra) because a large area of plantation was converted to a LULC

383 with lower carbon stock.

384 Temporal interval

385 The results are also sensitive to the interval period used between LULC map updates.

386 This has an impact on GHG emissions related to OSD. It has been shown that emissions 
387 from OSD can continue for an indefinite time period after conversion from a natural to

388 man-made state [20]. This process is sketched in Figure SM2, where emissions related to 389 soil degradation from the first stage of LUC continue into the second stage of LUC. It

390 has been observed that when OSD emissions from a previous period are not included,

391 GHG emissions can vary significantly. This has been analysed with CCI data for Central

392 Kalimantan, where GHG estimates derived for 5-yearly intervals (2000-2005 and 2005-

393 2010) were found to be approximately 1 million $\mathrm{Mg} \mathrm{C} / \mathrm{yr}$ higher than emissions summed

394 at intervals of 1 year, over the same 10-year period. This shows the GHG emission model

395 should incorporate LULC changes on organic soils predating the period of interest

396 wherever possible.

\section{Limitations in estimating GHG emissions}

398 The GHG emission estimates were calculated based on published carbon stock and 399 emission factors for different LULC classes. Variability and uncertainty in carbon stocks

400 can be observed in the range of literature values (Table SM2 and Table SM3) arising from

401 influences including of soil type and climate, or where different studies include different

402 elements of carbon pools [15]. Furthermore, peat soils may vary in depth and volume and 403 therefore influence carbon stocks [52]. Since the purpose of this study was to establish 404 uncertainty in GHG estimates resulting from the use of different LULC products, 405 variability and uncertainty in carbon stock values for different LULC classes were not 406 considered further.

407 Further work could be done to integrate variabilities in carbon stock accounting with the 408 variabilities in estimated LULC changes estimated in this study. Key considerations 409 would include spatial heterogeneity (edge effects) in above and belowground carbon 410 stocks within land cover classes [50, 51]; variability in water table depth and carbon loss 411 rates for OSD [20] and; uncertainties in emissions from land clearance fires on peat soils 
412 [19]. Emissions from degraded peat soils are known to continue a long period, often

413 longer than a typical LCA analysis period of 20-25 years [52]. Therefore, wherever

414 possible, it is advised to incorporate any known historic LULC changes on peat soils for

415 a period as long as possible.

416 The finding that LULC maps based on RS data interpretation differ is not new [40,41],

417 and some attempts have been made to improve comparability between LULC maps

418 [39]. A LULC dataset is always a trade-off between the input data quality and

419 accessibility, requirements of end-users and the technological and financial means

420 available for development. Each of these datasets represents a valuable source of

421 spatially explicit information for calculating GHG emissions related to LULC change.

422 The current variability between LULC maps suggests that estimates should be used to

423 provide a range rather than a single value for GHG emissions.

\section{Conclusions \& recommendations}

425 The need to quantify GHG emissions associated with LULC change is important for life

426 cycle assessments (LCA) of agricultural commodities and for providing evidence of

427 GHG reductions associated with zero net deforestation commitments. Without RS data,

428 such calculations would require detailed historical land records, and therefore these

429 datasets are valuable to estimate regional trends in LULC change and associated GHG

430 emissions. However, this study has shown the potential variability in estimates that can

431 be obtained through use of three open source RS datasets. These variabilities arise from

432 differences in EO input data, land classification methodologies, data resolution and

433 period of investigation. It is therefore advisable to compare different LULC datasets in

434 parallel and use the variability between GHG emission estimates as a confidence

435 interval, rather than a single value. Users should be aware of the potential for variability 
437 GHG emission maps, such as Figure 8, are useful visualisation tools that are not

438 commonly available and can provide spatial insight into LULC change and related

439 carbon emissions or sequestration. Current web-based platforms may show forest loss

440 or LULC for a given period, but, to our knowledge, do not yet provide maps showing

441 associated GHG emissions. Given the inconsistencies highlighted in this paper, there is

442 a need for further work to ensure the maps provide robust estimates of LULC change

443 and associated emissions.

444 The method described in this paper can be used to provide spatially-improved estimates

445 of LULC change and GHG emissions, particularly where the change occurs between

446 LULC types with significantly different carbon stock values, such as between primary

447 forest and plantation. For this to be most effective, there is a need for consensus

448 building and harmonisation on how to develop a consistent and robust approach to

449 assessing historic LULC change, to provide evidence for zero net deforestation

450 commitments, and refine GHG assessments.

451 We propose the following recommendations to improve LULC mapping for GHG 452 emission estimates for agricultural commodities:

453 Firstly, the LULC class definition should focus on LULC classes closely associated 454 with the main drivers of LULC change in the AOI. This should include at least the 455 following classes: primary \& secondary forest, several types of plantation (where 456 applicable), bare land and cropland. Global LULC datasets often use class definitions 457 that are too broad or lack specific class distinctions important for GHG modelling. 458 Additionally, class definitions of different LULC data sets should be more comparable.

459 The FAO LCCS definitions are developed to be globally relevant and flexible enough to 
460 suit most environments [55]. The CCI classes are based on LCCS, it could be useful for

461 other organisations involved in land cover mapping to adopt this system as well.

462 Secondly and ideally, maps should be updated at least every 2-3 years, and annual 463 updates would be preferable, to capture rapid changes, such as deforestation (fire or 464 logging), bare land, and plantation development.

465 Thirdly, to enable LULC change analysis over time, mapping methodology should 466 remain unchanged (a period of 20-25 years is required for LCA). If, for example, better

467 mapping algorithms are developed, such that the methodology can be improved 468 significantly, it would be preferable to reprocess the historic data to the new 469 methodology to maintain consistency.

470 Fourthly, optimal spatial resolution is dependent on the requirements of the user;

471 research on a provincial level can be done at lower spatial resolution than at smaller

472 scale, for example at plantation level. For studies related to a specific agri-food industry

473 it is often sufficient to focus on datasets with a spatial coverage of the main producing 474 areas.

475 Finally, metadata including quality and methodological information should be published 476 with the datasets.

477 When the three LULC datasets are compared against these recommendations, it is clear 478 there is currently room for improvement. Signs of improvements are visible, as the 479 recent reprocessing of the European Space Agency's CCI Land Cover initiative has 480 shown. As RS capabilities are advancing quickly and the importance of LULC change 481 analysis is becoming better recognised, this is an excellent time to address these 482 recommendations to make LULC data an even more valuable resource for 
483 environmental monitoring. 


\section{References}

485 1. Joshi N, Baumann M, Ehammer A, et al. A review of the application of optical and radar remote sensing data fusion to land use mapping and monitoring. Remote Sens. 8(1), 1-23 (2016).

2. Carlson KM, Curran LM, Ratnasari D, et al. Committed carbon emissions, deforestation, and community land conversion from oil palm plantation

3. Anderson JR. A land use and land cover classification system for use with remote

4. Kim C. Land use classification and land use change analysis using satellite images in Lombok Island, Indonesia. Forest Sci. Technol. [Internet]. 12(4), 183-

5. Srivastava PK, Han D, Rico-Ramirez MA, Bray M, Islam T. Selection of

6. Kuenzer C, van Beijma S, Gessner U, Dech S. Land surface dynamics and environmental challenges of the Niger Delta, Africa: Remote sensing-based analyses spanning three decades (1986-2013). Appl. Geogr. (2014).

7. Sameen MI, Nahhas FH, Buraihi FH, Pradhan B, Shariff ARBM. A refined classification approach by integrating Landsat Operational Land Imager (OLI) and RADARSAT-2 imagery for land-use and land-cover mapping in a tropical area. Int. J. Remote Sens. [Internet]. 37(10), 2358-2375 (2016). Available from:

510 8. Okamoto K, Kawashima H. Estimation of rice-planted area in the tropical zone using a combination of optical and microwave satellite sensor data. Int. J. Remote Sens. (1999).

513 9. Erasmi S, Twele a. Regional land cover mapping in the humid tropics using combined optical and SAR satellite dataa case study from Central Sulawesi, 
Indonesia. Int. J. Remote Sens. [Internet]. 30(10), 2465--2478 ST-- Regional land cover mapping in th (2009). Available from: http://www.tandfonline.com/doi/abs/10.1080/01431160802552728.

10. van Beijma S, Comber A, Lamb A. Random forest classification of salt marsh vegetation habitats using quad-polarimetric airborne SAR, elevation and optical RS data. Remote Sens. Environ. [Internet]. 149, 118-129 (2014). Available from: http://www.sciencedirect.com/science/article/pii/S0034425714001485.

11. Dong J, Xiao X, Sheldon S, Biradar C, Xie G. Mapping tropical forests and rubber plantations in complex landscapes by integrating PALSAR and MODIS imagery. ISPRS J. Photogramm. Remote Sens. (2012).

12. Balzter H, Cole B, Thiel C, Schmullius C. Mapping CORINE land cover from Sentinel-1A SAR and SRTM digital elevation model data using random forests.

13. Haack BN, Herold ND, Bechdol M a. Radar and Optical Data Integration for Land-Use / Land-Cover Mapping. Photogramm. Eng. Remote Sensing. (2000).

14. Maria Roman-Cuesta R, Rufino M, Herold M, et al. Hotspots of gross emissions from the land use sector: Patterns, uncertainties, and leading emission sources for the period 2000-2005 in the tropics. Biogeosciences. 13(14), 4253-4269 (2016).

15. Agus F, Henson IE, Sahardjo BH, et al. Review of emission factors for assessment of $\mathrm{CO} 2$ emission from land use change to oil palm in Southeast Asia. Reports from Tech. Panels 2nd Greenh. Gas Work. Gr. Roundtable Sustain. Palm Oil ( RSPO ) [Internet]. , 7-28 (2013). Available from: http://www.rspo.org/file/GHGWG2/3_review_of_emission_factors_Agus_et_al.p df.

16. Germer J, Sauerborn J. Estimation of the impact of oil palm plantation establishment on greenhouse gas balance. Environ. Dev. Sustain. 10(6), 697-716 (2008).

542 17. FAO. Crops processed; Indonesia and World total; Oil, palm; Production quantity; 2014. [Internet]. FAOSTAT. (2016). Available from: http://www.fao.org/faostat/en/?\#data/QD.

545 18. Page SE, Rieley JO, Banks CJ. Global and regional importance of the tropical 
peatland carbon pool. Glob. Chang. Biol. 17(2), 798-818 (2011).

547

19. Miettinen J, Hooijer A, Vernimmen R, Liew SC, Page SE. From carbon sink to carbon source: extensive peat oxidation in insular Southeast Asia since 1990. Environ. Res. Lett. [Internet]. 12(2), 24014 (2017). Available from: http://stacks.iop.org/17489326/12/i=2/a=024014?key=crossref.d5803ab4c180cc18647fc14663f0d775.

20. Hooijer A, Page S, Canadell JG, et al. Current and future CO 2 emissions from drained peatlands in Southeast Asia. Biogeosciences. 7(5), 1505-1514 (2010).

21. Miettinen J, Shi C, Liew SC. 2015 Land cover map of Southeast Asia at $250 \mathrm{~m}$ spatial resolution. Remote Sens. Lett. 7(7), 701-710 (2016).

22. Carlson KM, Curran LM, Asner GP, Pittman AM, Trigg SN, Marion Adeney J. Carbon emissions from forest conversion by Kalimantan oil palm plantations. Nat. Clim. Chang. [Internet]. 3(3), 283-287 (2012). Available from: http://www.nature.com/doifinder/10.1038/nclimate1702.

23. Gunarso P, Hartoyo ME, Agus F, Killeen TJ. Oil Palm and Land Use Change in Indonesia , Malaysia and Papua New Guinea. Reports from Tech. Panels RSPOs 2nd Greenh. Gas Work. Gr. , 29-64 (2013).

24. Koh LP, Miettinen J, Liew SC, Ghazoul J. Remotely sensed evidence of tropical peatland conversion to oil palm. Proc. Natl. Acad. Sci. [Internet]. 108(12), 51275132 (2011). Available from: http://www.pnas.org/cgi/doi/10.1073/pnas.1018776108.

25. Global Forest Watch. Oil palm concessions [Internet]. 2017. Available from: www.globalforestwatch.org.

26. ESA CCI. ESA CCI-Land Cover 2015 Product Users Guide Version 2.0 [Internet]. Available from: http://maps.elie.ucl.ac.be/CCI/viewer/download/ESACCI-LC-Ph2PUGv2_2.0.pdf.

27. Miettinen J, Shi C, Tan WJ, Liew SC. 2010 land cover map of insular Southeast Asia in 250-m spatial resolution. Remote Sens. Lett. (2012).

28. Hansen MC, Potapov P V., Moore R, et al. High-Resolution Global Maps of 21st-Century Forest Cover Change. Science (80-. ). [Internet]. 342(6160), 850- 
853 (2013). Available from:

29. Margono BA, Potapov P V, Turubanova S, Stolle F, Hansen MC. Primary forest cover loss in Indonesia over 2000-2012. Nat. Clim. Chang. (2014).

30. Hargrove WW, Hoffman FM, Hessburg PF. Mapcurves: A quantitative method for comparing categorical maps. J. Geogr. Syst. 8(2), 187-208 (2006).

31. Khasanah N, van Noordwijk M, Ningsih H, Rahayu S. Carbon neutral? No change in mineral soil carbon stock under oil palm plantations derived from forest or non-forest in Indonesia. Agric. Ecosyst. Environ. [Internet]. 211, 195206 (2015). Available from: http://dx.doi.org/10.1016/j.agee.2015.06.009.

32. IPCC. 2006 IPCC Guidelines for National Greenhouse Gas Inventories, Volume4: Agriculture, Forestry and Other Land Use. .

33. Ziegler AD, Phelps J, Yuen JQ, et al. Carbon outcomes of major land-cover transitions in SE Asia: Great uncertainties and REDD+ policy implications. Glob. Chang. Biol. (2012).

34. Agus F, Gunarso P, Sahardjo BH, Harris N, Noordwijk M Van, Killeen TJ. Historical Co 2 Emissions From Land Use and Land Use Change From the Oil Palm Industry in Indonesia , Malaysia and Papua New Guinea. , 65-88 (2010).

35. IPCC. 2006 IPCC Guidelines for National Greenhouse Gas Inventories [Internet]. Available from: https://www.ipcc-nggip.iges.or.jp/public/2006gl/.

36. Hooijer A, Page S, Jauhiainen J, et al. Subsidence and carbon loss in drained tropical peatlands. Biogeosciences. 9(3), 1053-1071 (2012).

37. Page SE, Siegert F, Rieley JO, Boehm H-D V, Jaya A, Limin S. The amount of carbon released from peat and forest fires in Indonesia during 1997. Nature [Internet]. 420, 61 (2002). Available from: http://dx.doi.org/10.1038/nature01131.

38. Moore S, Evans CD, Page SE, et al. Deep instability of deforested tropical peatlands revealed by fluvial organic carbon fluxes. Nature [Internet]. 493(7434), 660-663 (2013). Available from: http://dx.doi.org/10.1038/nature11818.

39. See LM, Fritz S. A method to compare and improve land cover Datasets: 
607

608

609

610

611

612

613

614

615

616

617

618

619

620

621

622

623

624

625

626

627

628

629

630

631

632

633

634

635

636

Application to the GLC-2000 and MODIS land cover products. IEEE Trans. Geosci. Remote Sens. 44(7), 1740-1746 (2006).

40. Giri C, Zhu Z, Reed B. A comparative analysis of the Global Land Cover 2000 and MODIS land cover data sets. Remote Sens. Environ. 94(1), 123-132 (2005).

41. DeVisser MH, Messina JP. Optimum land cover products for use in a Glossinamorsitans habitat model of Kenya. Int. J. Health Geogr. [Internet]. 8(1), 39 (2009). Available from: http://ijhealthgeographics.biomedcentral.com/articles/10.1186/1476-072X-8-39.

42. Townshend J, Justice C, Li W, Gurney C, McManus J. Global land cover classification by remote sensing: present capabilities and future possibilities. Remote Sens. Environ. 35(2-3), 243-255 (1991).

43. Salomonson V V, Barnes W, Xiong J, Kempler S, Masuoka E. An overview of the Earth Observing System MODIS instrument and associated data systems performance. IEEE Int. Geosci. Remote Sens. Symp. 2(C), 1174-1176 (2002).

44. Roy DP, Wulder MA, Loveland TR, et al. Landsat-8: Science and product vision for terrestrial global change research. Remote Sens. Environ. 145, 154-172 (2014).

45. Whiteside T. a Comparison of Object-Oriented and Pixel-Based Classification Methods for Mapping Land Cover. (September), 1225-1231 (2005).

46. Myint SW, Gober P, Brazel A, Grossman-Clarke S, Weng Q. Per-pixel vs. object-based classification of urban land cover extraction using high spatial resolution imagery. Remote Sens. Environ. 115(5), 1145-1161 (2011).

47. Foody GM. Status of land cover classification accuracy assessment. Remote Sens. Environ. 80(1), 185-201 (2002).

48. Arnot C, Fisher P. Mapping the ecotone with fuzzy sets. In: NATO Security through Science Series C: Environmental Security. , 19-32 (2007).

49. Davis SJ, Burney JA, Pongratz J, Caldeira K. Methods for attributing land-use emissions to products. Carbon Manag. 5(2), 233-245 (2014).

50. The British Standards Institution; PAS 2050:2011; Specification for the assessment of the life cycle greenhouse gas emissions of goods and services. . 
637 51. GanLian T, Cai H. Calculating GHG emission in oil palm using PalmGHG.

$638 \quad$ Planter. 93(1092), 167-176 (2017).

639 52. Page SE, Banks CJ, Rieley JO. Tropical Peatlands: Distribution, Extent and

640 Carbon Storage - Uncertainties and Knowledge Gaps. Peatlands Int. 2(2), 26-27

$641 \quad$ (2007).

642 53. Chaplin-Kramer R, Ramler I, Sharp R, et al. Degradation in carbon stocks near 643 tropical forest edges. Nat. Commun. 6 (2015).

644 54. Brinck K, Fischer R, Groeneveld J, et al. High resolution analysis of tropical 645 forest fragmentation and its impact on the global carbon cycle. Nat. Commun. 8 $646 \quad$ (2017).

647 55. Gregorio A Di, Henry M, Donegan E, et al. Classification Concepts Land Cover 648 Classification System Software version 3. Available from: www.fao.org/. 649 
651 Table 1 - Geographical extent and area of peat soil cover [19] and PO concessions [25] 652 of the study areas

\begin{tabular}{|c|c|c|c|c|c|c|c|}
\hline Province & $\begin{array}{l}\text { Total area } \\
\text { (ha) }\end{array}$ & $\begin{array}{l}\text { Peat soil } \\
\text { area (ha) }\end{array}$ & $\begin{array}{l}\text { Peat } \\
\text { (\% of } \\
\text { total } \\
\text { area) }\end{array}$ & $\begin{array}{l}\text { PO } \\
\text { concession } \\
\text { area (ha) }\end{array}$ & $\begin{array}{l}\text { PO } \\
\text { concession } \\
\text { (\% of } \\
\text { total area) }\end{array}$ & $\begin{array}{l}\text { PO on } \\
\text { peat soil } \\
\text { (ha) }\end{array}$ & $\begin{array}{l}\text { PO on } \\
\text { peat }(\% \text { of } \\
\text { total } \\
\text { concession } \\
\text { area) }\end{array}$ \\
\hline North & & & & & & & \\
\hline Sumatra & $7,243,839$ & 347,925 & 4.8 & 132,538 & 1.8 & 61,203 & 46.2 \\
\hline Riau & $8,995,724$ & $4,004,336$ & 44.5 & $2,117,307$ & 23.5 & 819,769 & 38.7 \\
\hline Central & & & & & & & \\
\hline Kalimantan & $15,354,930$ & $3,005,097$ & 19.6 & $3,199,420$ & 20.8 & 464,079 & 14.5 \\
\hline
\end{tabular}


654 Table 2 - Overview of LULC datasets used in this research

\begin{tabular}{|c|c|c|c|c|c|}
\hline Organisation & $\begin{array}{l}\text { Acrony } \\
\text { m }\end{array}$ & $\begin{array}{l}\text { Spatial } \\
\text { resolution } \\
\text { (m) }\end{array}$ & $\begin{array}{l}\text { Spatial } \\
\text { extent }\end{array}$ & Updates & $\begin{array}{l}\text { URL data } \\
\text { repository }\end{array}$ \\
\hline $\begin{array}{l}\text { European Space } \\
\text { Agency (ESA) } \\
\text { Climate Change } \\
\text { Initiative Land } \\
\text { Cover }\end{array}$ & $\mathrm{CCI}$ & $300 \times 300$ & Global & $\begin{array}{l}\text { Annual } \\
\text { between } \\
\text { 1992-2015 }\end{array}$ & $\begin{array}{l}\text { http://maps.elie.ucl } \\
\text { ac.be/CCI/viewer/ }\end{array}$ \\
\hline $\begin{array}{l}\text { Centre for Remote } \\
\text { Imaging, Sensing } \\
\text { and Processing, } \\
\text { Singapore }\end{array}$ & CRISP & $250 \times 250$ & $\begin{array}{l}\text { Southeast } \\
\text { Asia }\end{array}$ & $\begin{array}{l}2000,2010, \\
2015\end{array}$ & $\begin{array}{l}\text { https://ormt- } \\
\underline{\text { crisp.nus.edu.sg/or }} \\
\underline{\text { mt/Home/Disclaim }} \\
\underline{\text { er }}\end{array}$ \\
\hline $\begin{array}{l}\text { Indonesia Ministry } \\
\text { of Forestry }\end{array}$ & MoF & $\begin{array}{l}30 \times 30(100 \\
\times 100 \text { used } \\
\text { for this } \\
\text { research) }\end{array}$ & Indonesia & $\begin{array}{l}\text { 1990, 1996, } \\
2000,2003, \\
2006,2009, \\
2011,2012, \\
2013,2015\end{array}$ & $\begin{array}{l}\text { http://www.greenp } \\
\text { eace.org/seasia/id/ } \\
\text { Global/seasia/Indo } \\
\text { nesia/Code/Forest- } \\
\text { Map/en/index.html }\end{array}$ \\
\hline
\end{tabular}


656 Table 3 - Main contributors to LULC change for largest observed MoF LULC changes 657 for all AOIs.

\begin{tabular}{|l|l|l|l|l|l|}
\hline & & Total & Largest & & \\
AOI & Period & (ha) & LULC & & \\
change/yr & change/yr & From LULC class (t0) & \% of \\
North & $2006-2009$ & 638,860 & 407,018 & Dry Rice Land Mixed & 63.7 \\
\hline Sumatra & & & & --> to LULC class (t1) & total \\
\hline Riau & $2012-2013$ & $1,118,233$ & 726,066 & Scrubland --> Dry Rice & 64.9 \\
\hline Kalimantan & & & & Land Mixed w/Scrub & \\
\hline
\end{tabular}

658

659 
660 Table 4 - GHG emissions for three AOIs for 2000 - 2010/11, with \% of emissions from 661 mineral/peat

\begin{tabular}{|l|l|l|l|l|l|l|l|}
\hline \multicolumn{5}{|l|}{ Emissions per year (Mg C yr-1) and percent of total } \\
\hline North Sumatra (4.8 \% peat) & \multicolumn{5}{l|}{} \\
\hline Mineral & $1,332,803$ & 34.5 & $4,943,071$ & 58.7 & $1,127,552$ & 38.4 \\
\hline Peat & $2,526,168$ & 65.5 & $3,473,117$ & 41.3 & $1,807,528$ & 61.6 \\
\hline Total & $3,858,971$ & & $8,416,188$ & & $2,935,080$ & \\
\hline Riau (44.5 \% peat) & CCI (2000-2010) & CRISP (2000-2010) & MoF (2000-2011) \\
\hline Mineral & $9,533,167$ & 33.2 & $11,784,303$ & 28.7 & $4,812,749$ & 17.2 \\
\hline Peat & $19,174,983$ & 66.8 & $29,246,758$ & 71.3 & $23,105,593$ & 82.8 \\
\hline Total & $28,708,150$ & & $41,031,060$ & & $27,918,343$ & \\
\hline Central Kalimantan (19.6 \% peat) & & & \\
\hline
\end{tabular}

662 
663 Table 5 - GHG emissions for three AOIs for 2010/11 - 2015, with \% of emissions from 664 mineral/peat

\begin{tabular}{|c|c|c|c|c|}
\hline \multicolumn{5}{|c|}{ 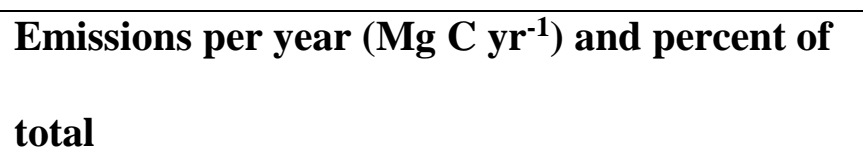 } \\
\hline \multicolumn{5}{|c|}{ North Sumatra (4.8\% peat) } \\
\hline & \multicolumn{2}{|c|}{ CCI (2010-2015) } & \multicolumn{2}{|c|}{ MoF (2011-2015) } \\
\hline Mineral & 491,500 & 47.8 & $3,450,122$ & 80.3 \\
\hline Peat & 536,465 & 52.2 & 845,314 & 19.7 \\
\hline Total & $1,027,966$ & & $4,295,435$ & \\
\hline \multicolumn{5}{|c|}{ Riau (44.5\% peat) } \\
\hline & \multicolumn{2}{|c|}{ CCI (2010-2015) } & \multicolumn{2}{|c|}{ MoF (2011-2015) } \\
\hline Mineral & $4,055,092$ & 32.12 & $6,200,630$ & 27.1 \\
\hline Peat & $8,571,629$ & 67.88 & $16,672,805$ & 72.9 \\
\hline Total & $12,626,721$ & & $22,873,435$ & \\
\hline \multicolumn{5}{|c|}{ Central Kalimantan (19.6 \% peat) } \\
\hline & \multicolumn{2}{|c|}{ CCI (2010-2015) } & \multicolumn{2}{|c|}{ MoF (2011-2015) } \\
\hline Mineral & $2,814,481$ & 58.5 & $10,357,934$ & 48.6 \\
\hline Peat & $1,994,610$ & 41.5 & $10,941,092$ & 51.4 \\
\hline Total & $4,809,091$ & & $21,299,027$ & \\
\hline
\end{tabular}



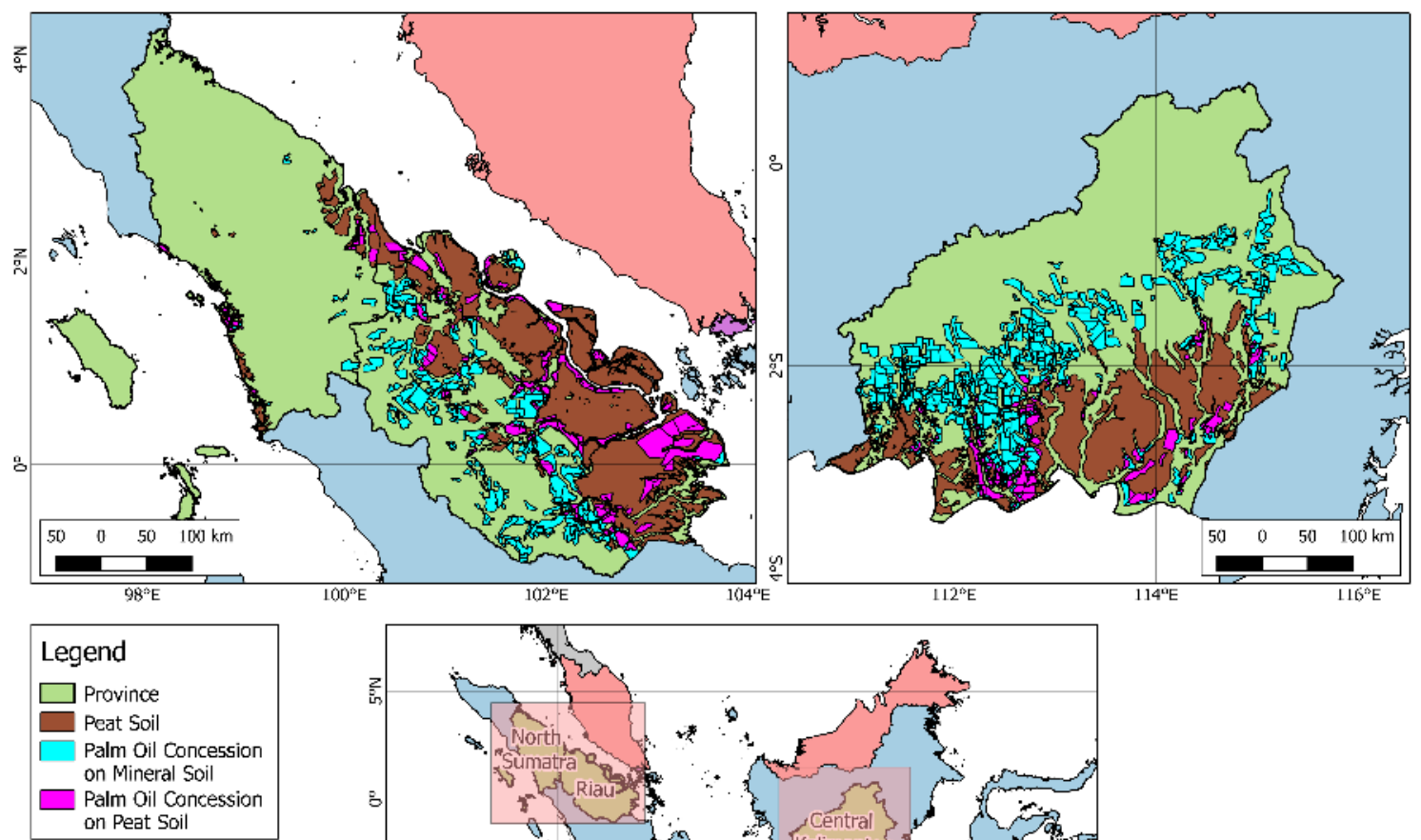

667

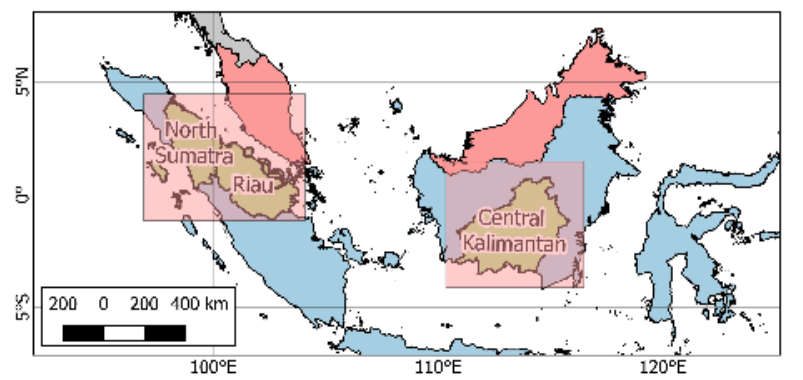

668 Figure 1 


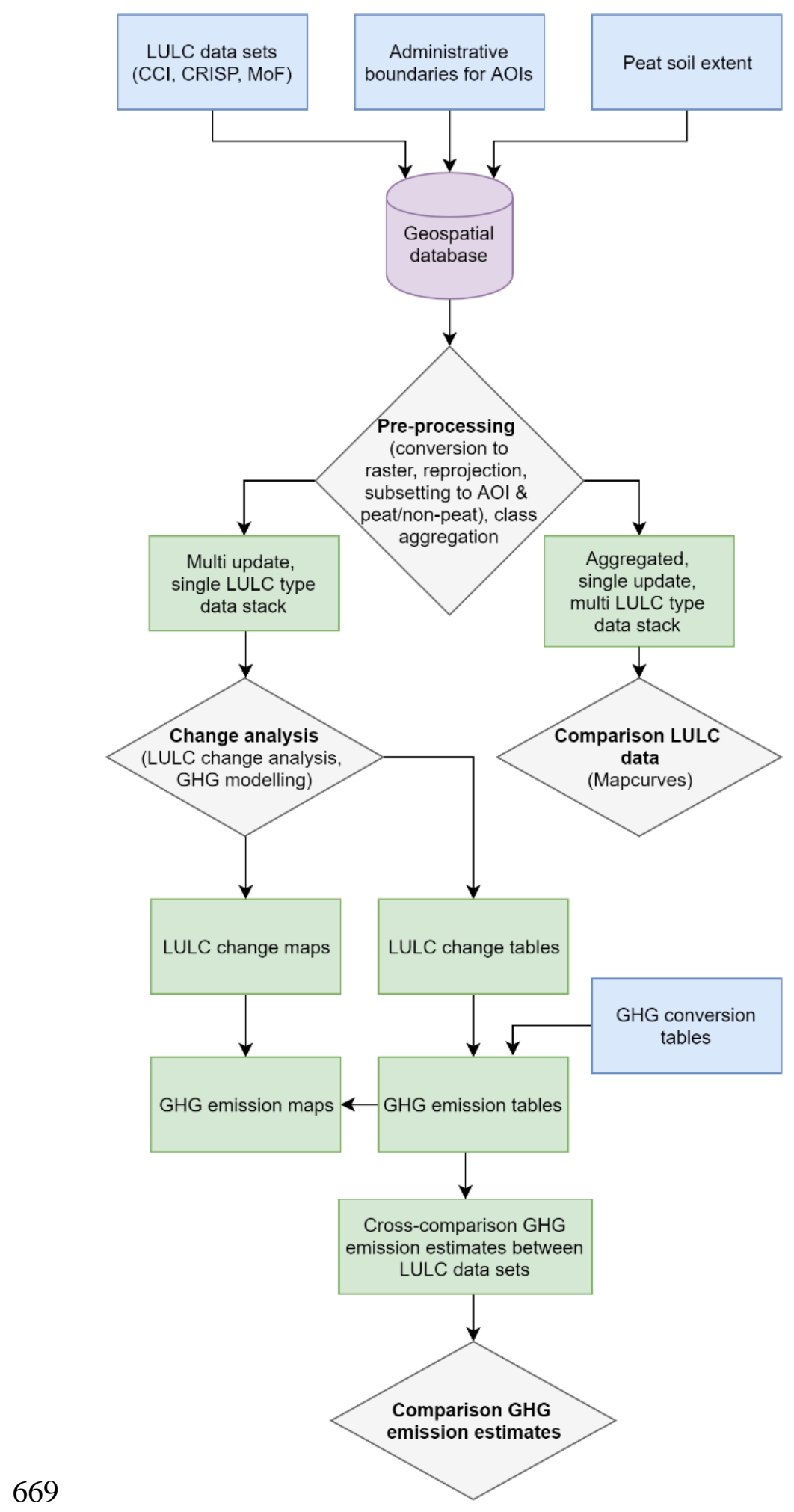

$670 \quad$ Figure 2 

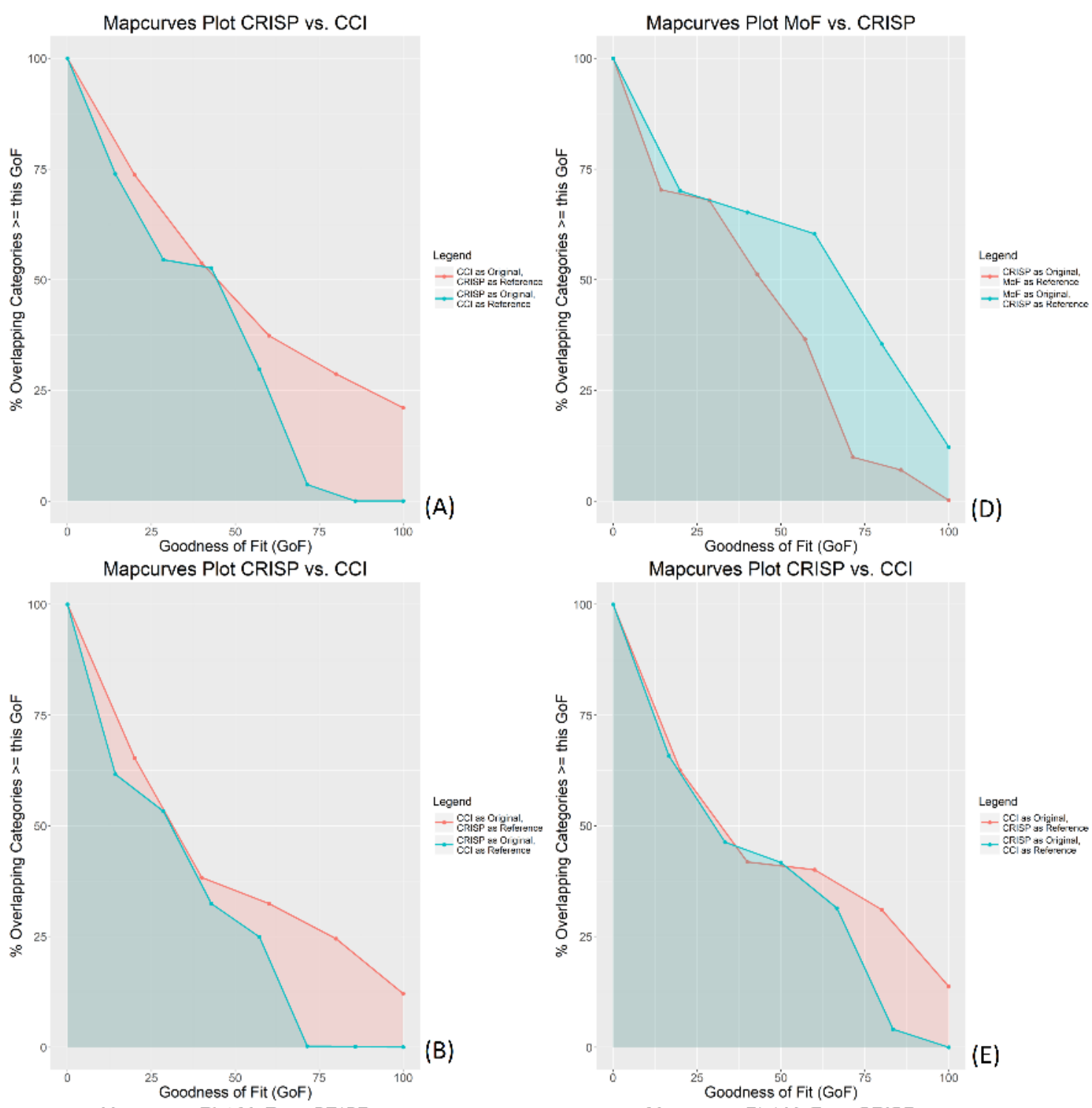

Legend

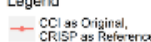

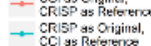
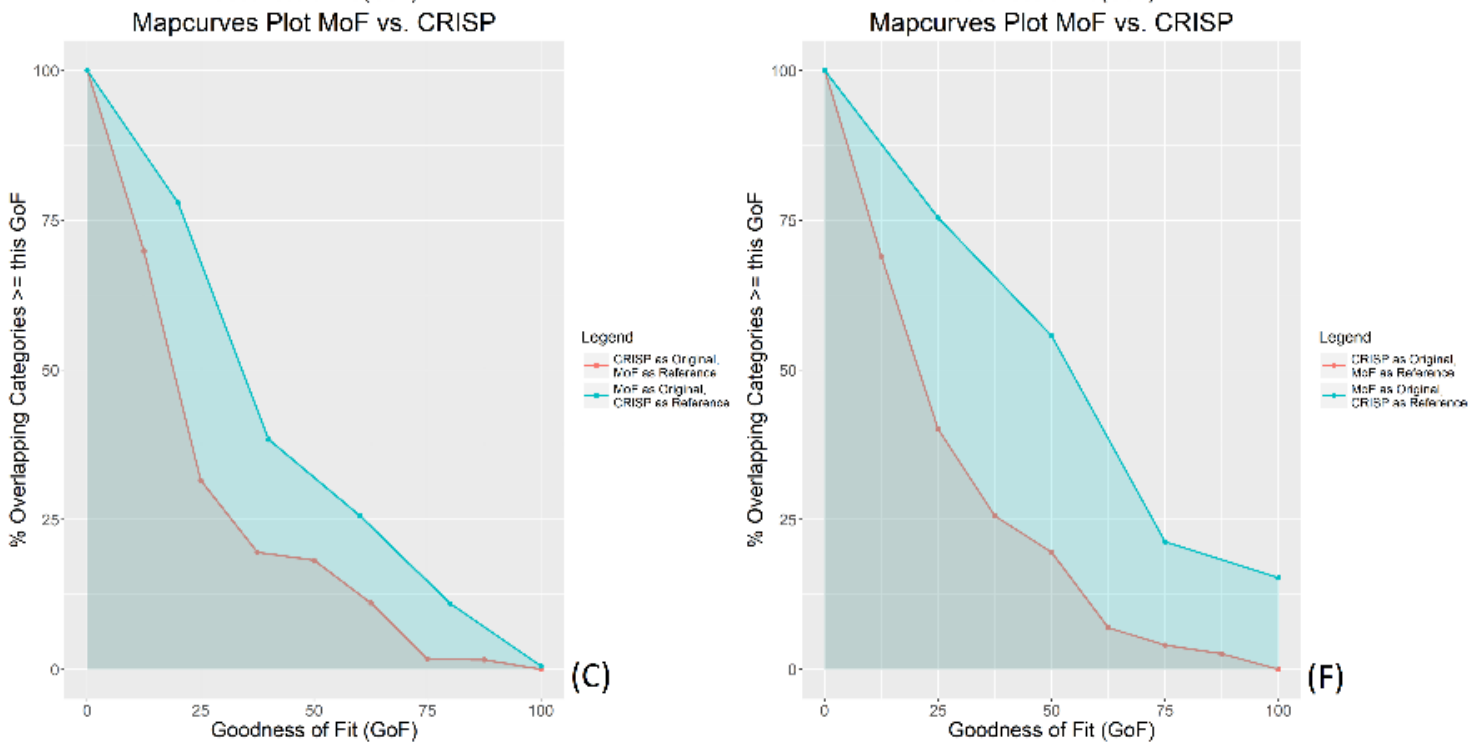

$672 \quad$ Figure 3 


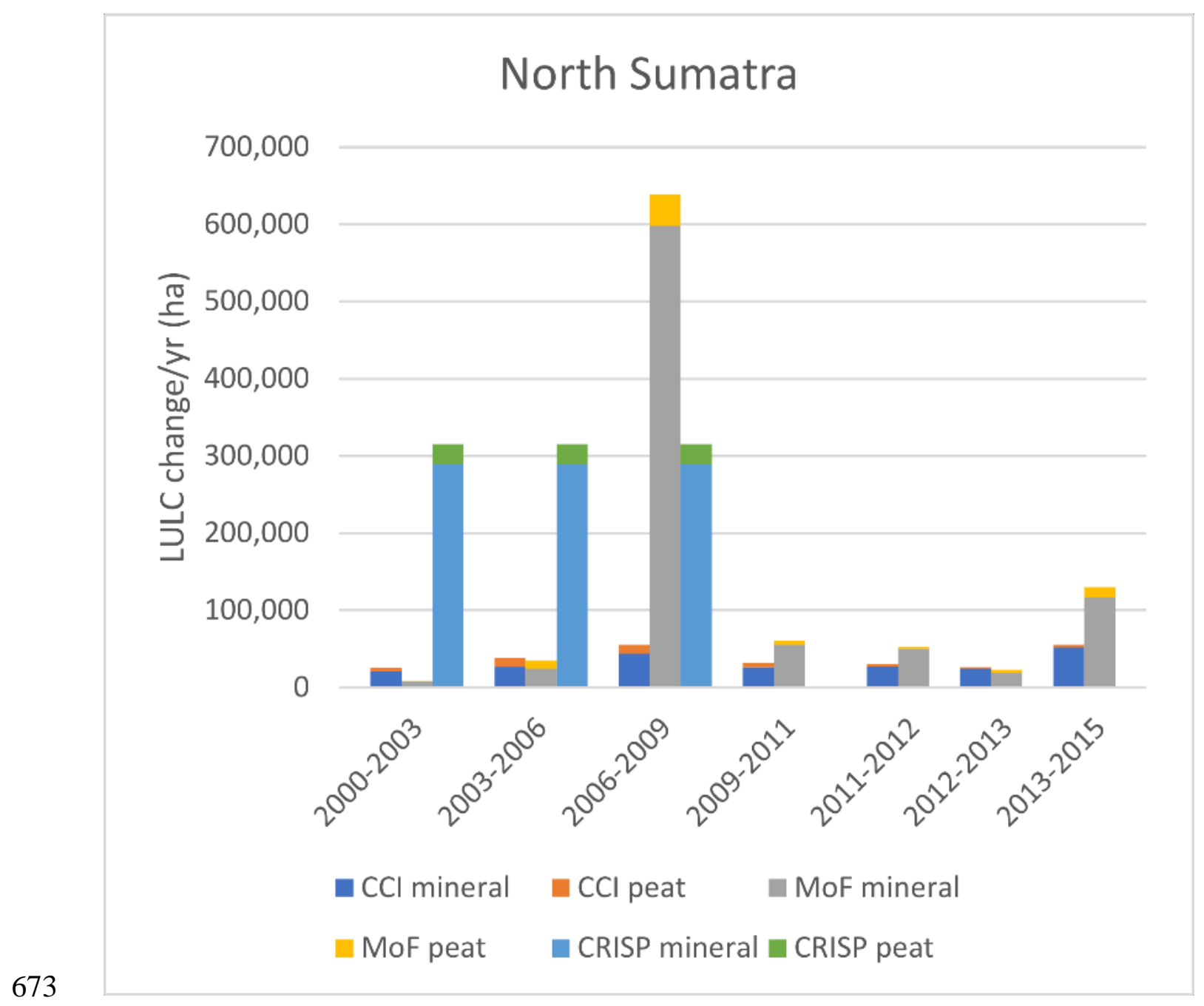

674 Figure 4 


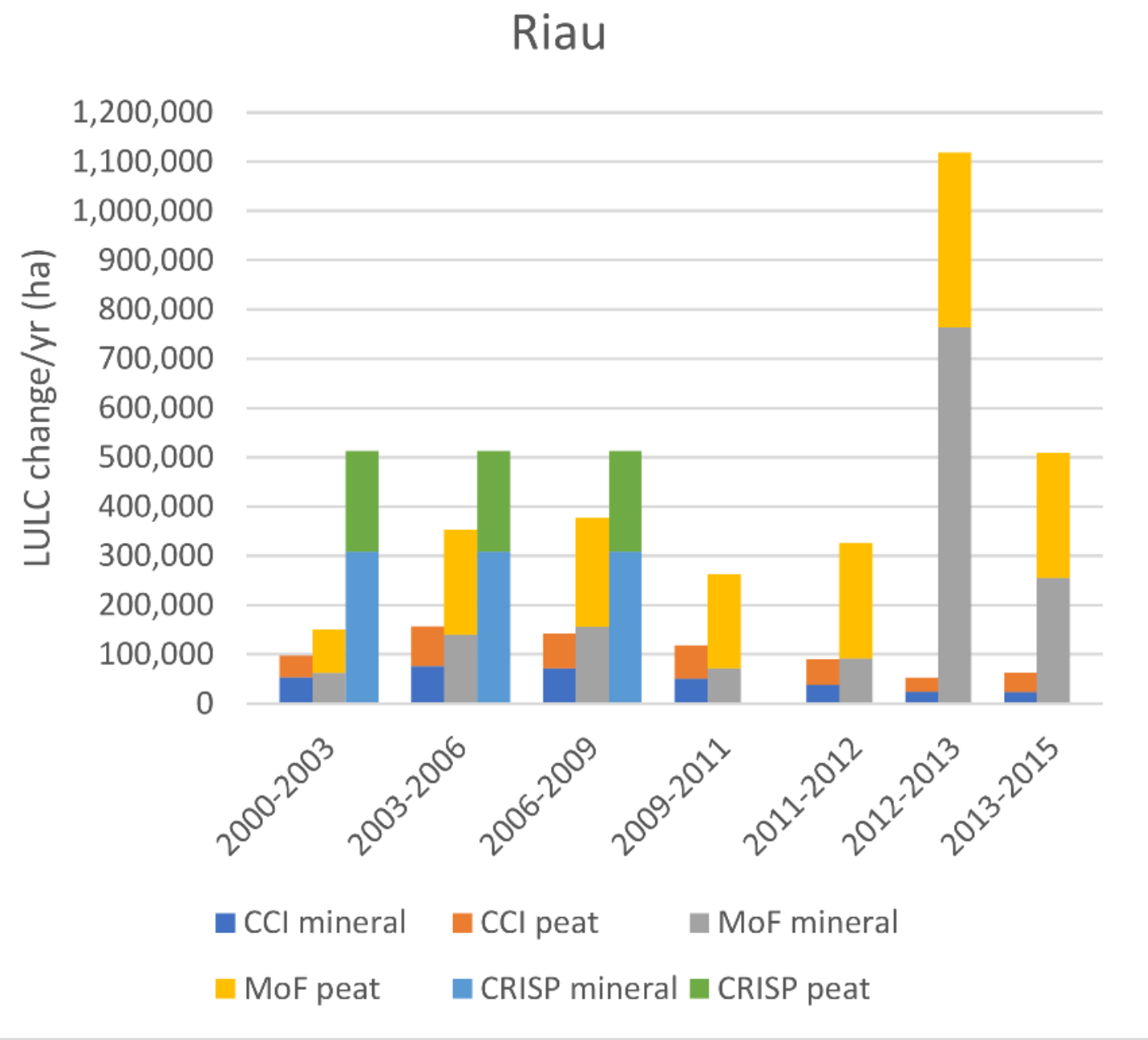

675

676 Figure 5 


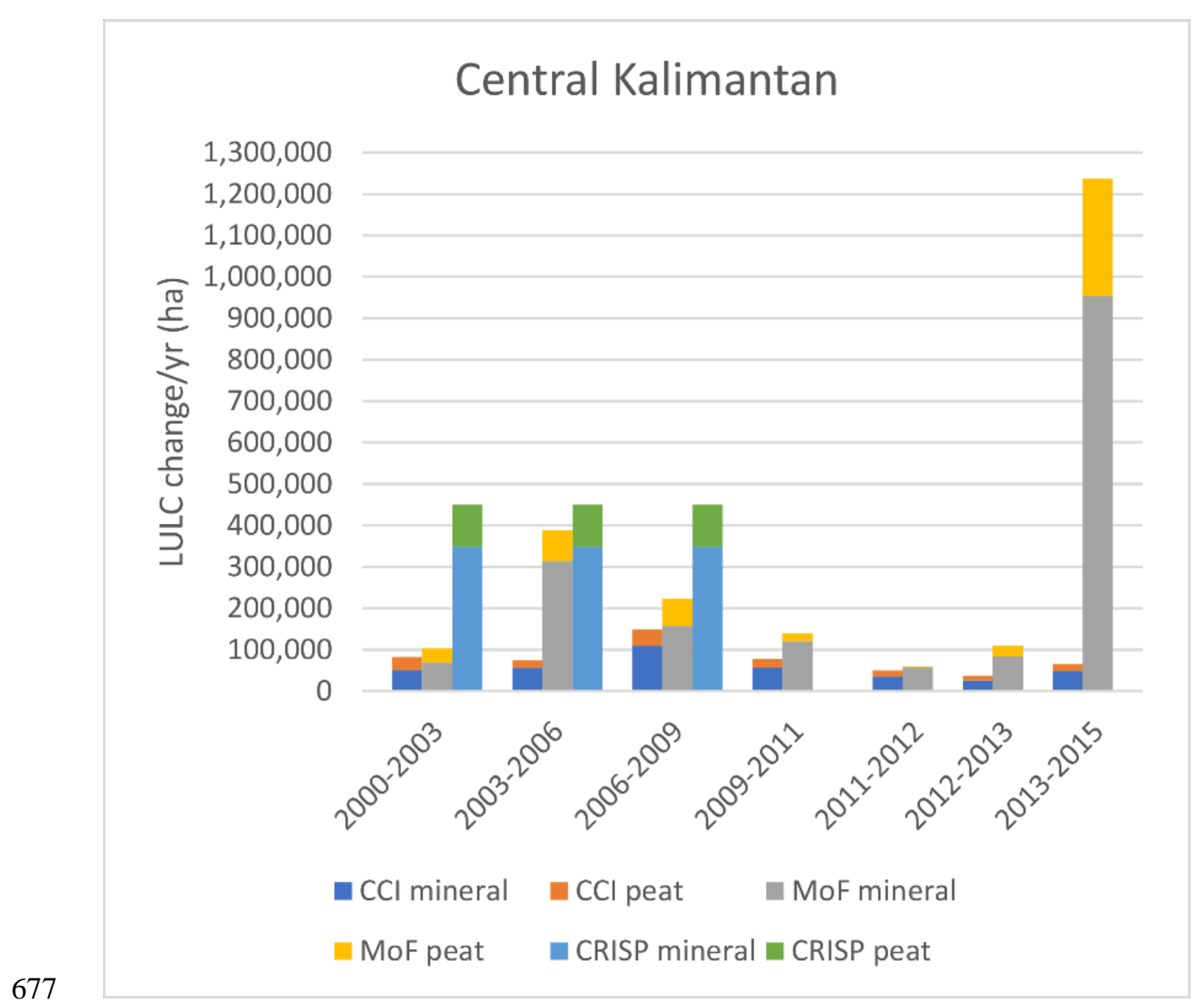

$678 \quad$ Figure 6 


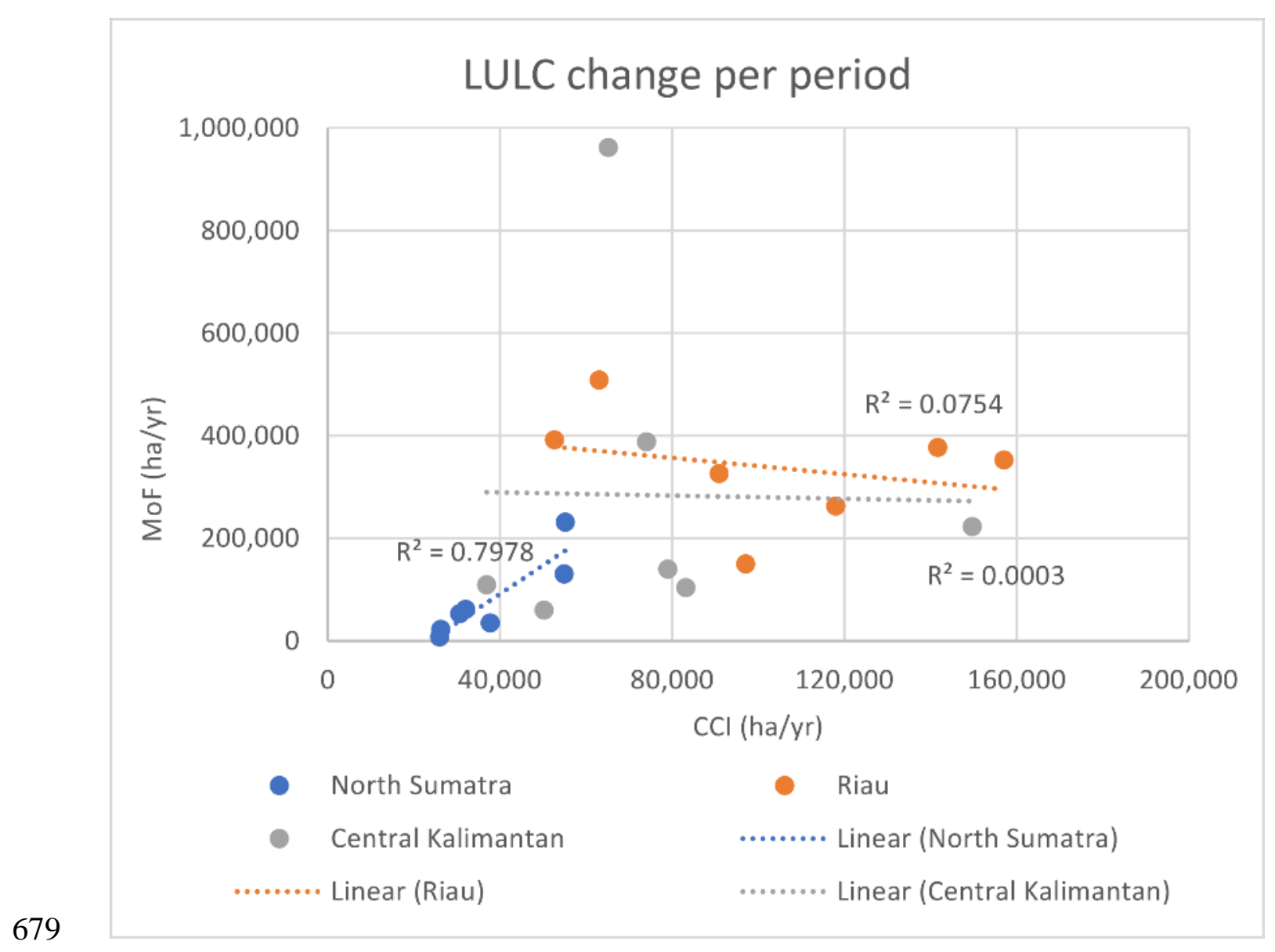

$680 \quad$ Figure 7 

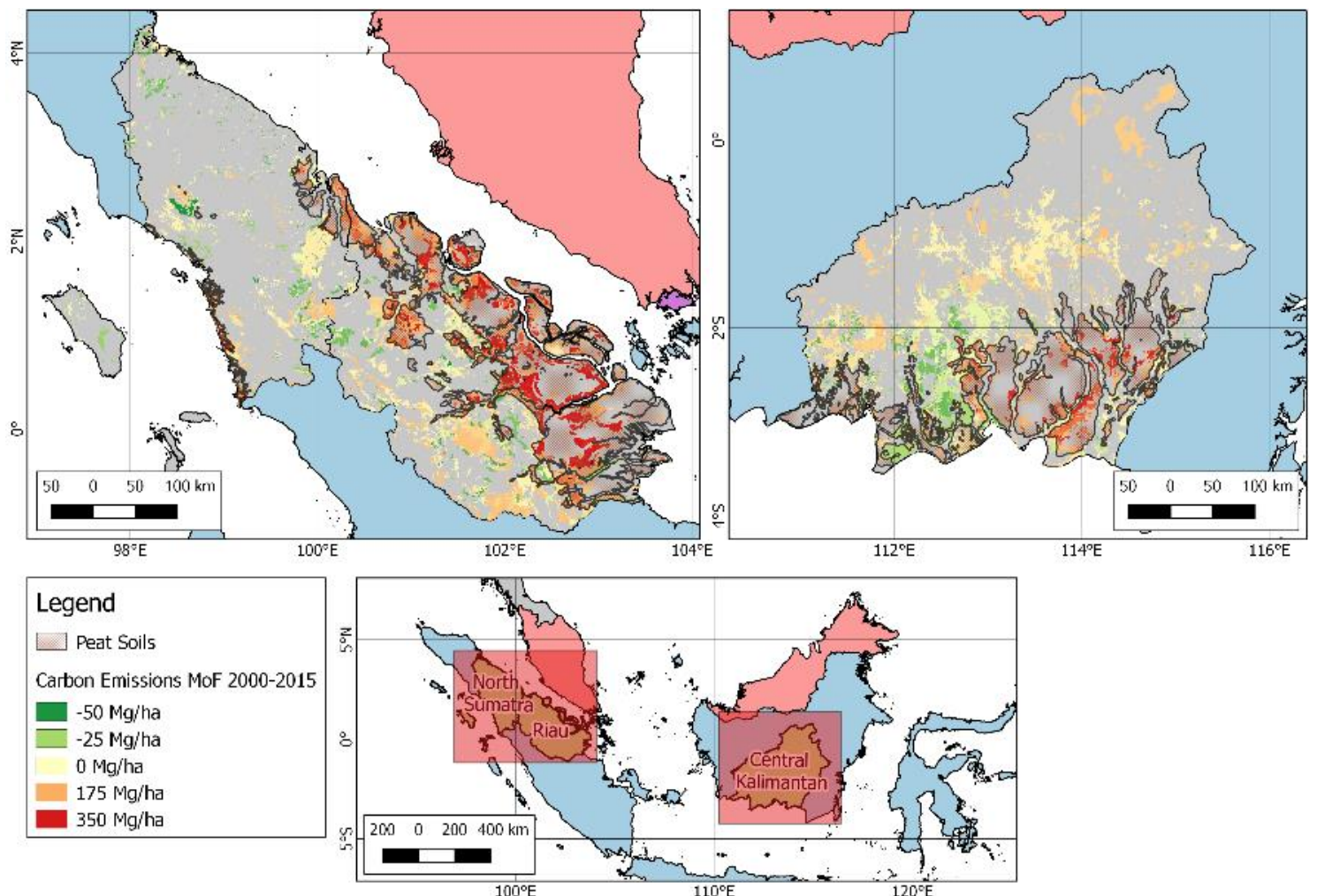

681

$682 \quad$ Figure 8 


\section{Figure captions}

684 Figure 1 - The AOIs in Indonesia, with PO plantation concessions and peat soil areas 685 indicated.

686 Figure 2 - Data analysis workflow diagram

687 Figure 3 - Best fitting mapcurve plots for North Sumatra (3a and 3d), Riau (3b and 3e)

688 and Central Kalimantan (3c and 3f) for 2000 and 2015, respectively

689 Figure 4 - LULC change in North Sumatra between 2000 and 2015

690 Figure 5 - LULC change in Riau between 2000 and 2015

691 Figure 6 - LULC change in Central Kalimantan between 2000 and 2015

692 Figure 7 - Scatter plot LULC change estimates in all three AOIs in the period 2000-

6932015 from CCI and MoF

694 Figure 8 - GHG emission map of AOIs, based on MoF data for the period 2000-2015 